This is the accepted version of the following article: Bloom, Taryn and Sharpe, Louise and Mullan, Barbara and Zucker, Nancy. 2013. A pilot evaluation of appetite-awareness training in the treatment of childhood overweight and obesity: A preliminary investigation.

International Journal of Eating Disorders. 46 (1): pp. 47-51, which has been published in final form at http://doi.org/10.1002/eat.22041 
Dr Taryn Bloom, School of Psychology, The University of Sydney Prof Louise Sharpe, School of Psychology, The University of Sydney

Dr Barbara Mullan, School of Psychology, The University of Sydney

Prof Nancy Zucker, Department of Psychiatry and Behavioral Sciences, Duke University Medical Center

Running Head: A RANDOMIZED CONTROLLED EVALUATION OF APPETITEAWARENESS TRAINING 


\begin{abstract}
Objective: The aim of this study was to conduct a preliminary evaluation of Children's Appetite Awareness Training (CAAT), a treatment for childhood obesity which encourages overweight children to eat in response to internal appetite cues. Method: Overweight children (ages $6-12$ years old) were randomized to either the CAAT treatment group $(\mathrm{N}=23)$, to receive one-hour treatment sessions over six weeks, or a wait-list group $(\mathrm{N}=24)$. Weight and height of children and parents in both groups were assessed at pre- and post-treatment (or equivalent time for wait-list control) and at a six-month follow-up for those in the CAAT group. Results: The intervention had a significant, short-term effect on the weight of children who participated. Although at six-month follow-up, children's BMI has not increased significantly, the difference between pretreatment and follow-up BMI was no longer significant. Discussion: These results are encouraging for the use of CAAT with overweight children. Long-term effectiveness could be enhanced through increasing the duration of the program, adding booster sessions and increased involvement of parents.
\end{abstract}




\section{A randomized controlled evaluation of appetite-awareness training in the treatment of childhood overweight and obesity: A preliminary investigation}

Childhood obesity is the most prevalent nutritional disease in developed countries (1.) and has been designated a global epidemic (2; 3.). In Australia, the prevalence of children who are either obese or overweight has increased over the last 25 years. Recent Australian studies have found that $5.9 \%$ of girls and $5.3 \%$ of boys are obese and a further $16-18 \%$ of girls and $14-16 \%$ of boys are overweight (4; 5.). Childhood obesity usually continues into adulthood and has been associated with an increased risk of multi-systemic disease, including orthopaedic, gastrointestinal, immunological, metabolic, respiratory and sleeprelated problems $(1 ; 6-10$.$) . Thus, there is a critical need to develop treatment$ and prevention strategies in childhood.

Epstein (11.) has commented that methods for improving the selfregulation of energy intake amongst children have been almost entirely neglected, despite evidence that overweight children are poorer at regulating their own food intake compared to normal-weight children (12; 13.). Such emphasis is particularly imperative given broad, detrimental changes to the environment that promote food overconsumption (e.g. portion sizes, food advertising, pervasive environmental cues to eat, easy accessibility of foodstuffs low in nutrient density). Given that broad policy changes are unlikely to occur quickly enough to impact contemporary children, there is an imperative need to enhance their capacity to resist environmental cues to eat when not biologically hungry. Critically, Johnson (14.) found that both children who over-ate and those who under-ate could be 
taught to better regulate their eating from as young as eight years. However, it remains an unknown as to whether treatments based on self-regulation of appetite may be efficacious in the treatment of childhood overweight and obesity.

One approach designed to enhance self-regulatory capacities in adults is 'Appetite-Focused Cognitive Behavioural Therapy' (CBT-AF) (15.). CBT-AF is based on the premise that individuals who are overweight and obese often eat in response to situational or external cues, rather than eating when they are hungry and stopping when they are full $(16 ; 17$.$) CBT-AF teaches participants skills to$ encourage eating in response to moderate internal hunger and satiety cues thus improving self-regulation of energy intake (15.). CBT-AF has been found to reduce binge-eating and reduce weight gain in patients with Binge-Eating Disorder $(8 ; 15 ; 18$.$) . A recent randomized controlled trial using an adapted form$ of the CBT-AF demonstrated some efficacy (19.), but this was trialled among an adult population. Boutelle et al. (20.) compared children's appetite awareness training (CAAT), an adapted version of CBT-AF for children, to cue exposure treatment among overweight or obese children (8 to 12 years). Both treatments resulted in significant reductions in binge-eating, indicating that these treatments may have potential in the management of childhood overweight and obesity. However, no changes were found for caloric intake. The authors acknowledged that this was these data were preliminary and recommended further research into these novel treatments.

The aim of this study was to investigate further the efficacy of the CAAT program, in the treatment of childhood overweight and obesity using a 
randomised controlled trial. CAAT is designed to resensitise children to recognize and respond to their internal appetite signals cues (i.e. hunger and satiety) and thereby improve their self-regulation of energy intake. The impact of the intervention on parents' weight was also of interest; a recent review of the literature considering the role of parents in their children's food choices concluded that despite some innate food preference, the majority of children's food behaviours are learned (21.). It was therefore hypothesized that, following the intervention period, children receiving CAAT would have relative weight loss compared to children in the control group and parents of children receiving CAAT would have weight loss compared to the parents of children in the control group.

\section{Methods}

\section{Participants}

Participants were recruited through advertisements in newspapers, magazines and radio interviews. Overweight or obesity in children is defined by an age-related BMI above the percentile passing through BMI values of $25 \mathrm{~kg} / \mathrm{m}^{2}$ or $30 \mathrm{~kg} / \mathrm{m}^{2}$ at 18 years, respectively (22.). Overweight or obese children, between 7 and 12 years were eligible for the study. Children enrolled in another weight control treatment or those with mental health problems (screened for by Psychologists) that warranted treatment were excluded.

Ninety-one parents telephoned the clinic to inquire about the program and 45 attended an assessment. Children were stratified by age (6-9, 10-12) and then randomized to the CAAT treatment group or wait-list group. The 
randomization sequence was generated by one of the authors (LS) using the Bernoulli function (0.05) while another author (TB) enrolled participants. At the assessment, each consecutive child was given a participant number linked to a random number that was concealed until after the assessment. Twenty-four children were allocated to the wait-list group and twenty-three to CAAT (See Figure 1). Data for all children in both groups were available for pre- and posttreatment (or equivalent time for wait-list). Of the children assigned to CAAT, some $(n=5)$ did not attend all sessions or did not attend the six-month follow-up $(n=4)$. Those in the wait-list group were offered treatment during follow-up.

\section{FIGURE 1 NEAR HERE}

\section{Procedure}

At baseline, all families participated in an assessment session in which children and parents signed consent forms. The weight and height of children and parents in both groups were measured to determine their BMI, using an electronic scale, at the first assessment and at the final treatment session (or equivalent time for wait-list). Those in the CAAT group were also measured six

months following treatment. The child's BMI was the primary outcome measure, with parental BMI the secondary outcome.

\section{Treatment}

The treatment program was adapted for children from Craighead and Allen's (15.) CBT-AF program. For the CAAT group, children and at least one 
parent received six, one-hour group sessions of Children's Appetite Awareness Training (CAAT) delivered over a 6-week period. The intervention was conducted at the Psychology Clinic at the University of Sydney. Group sessions (3-7 children per group) were conducted by two Intern Clinical Psychologists. Another intern clinical psychologist ran a parent group concurrently in which the content of the program was explained to them and they were encouraged to adopt a whole family approach to appetite awareness. Participants did not pay for their treatment. Two experienced clinical psychologists supervised the treatment and observed all sessions. The session-by-session guide is described below (23.).

Session 1 - The aim of this session was to establish awareness of internal appetite cues. Children were introduced to a hunger meter (See Figure 2) and encouraged to monitor their appetite daily. Children were encouraged to start and stop eating at a moderate (not extreme) level of hunger and fullness.

\section{FIGURE 2 NEAR HERE}

Session 2-The aim of this session was to establish eating in response to hunger. In an attempt to show how difficult it is to stop eating when you are "starving", children were asked to miss breakfast and attended the session with their lunch. Children were encouraged to eat regularly before their body became too hungry.

Session 3 - The aim of this session was to identify reasons that people eat other than hunger (e.g., boredom, presence of food nearby). Children were 
taught about "true" and "tricky" hunger and different traps that lead people to eat when they are not hungry. Problem-solving was introduced as a method to think of alternative activities other than eating.

Session 4 - The aim of this session was to introduce cognitive and behavioural strategies to minimise episodes of emotional, impulsive and/or "sneak" eating. The group brainstormed ways to avoid the traps through problemsolving.

$\underline{\text { Session } 5}-$ The target of this session was self-acceptance. Children identified personal strengths, constructed helpful attitudes about themselves, and learned to reward themselves for change.

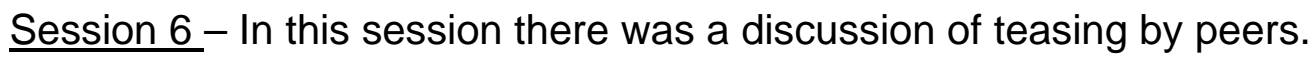
Cognitive challenging was used when appropriate and strategies to help deal with bullies were practiced. Children were encouraged to plan for future triggers that may stop them using their hunger meters.

\section{Statistical Analysis}

Independent sample t-tests were used to determine baseline differences on demographic and BMI variables between intervention and wait-list control groups. Any differences between groups were statistically controlled in the main analyses. Repeated measures 2 (group: treatment vs. control) $\times 2$ (time: pre- vs. post-) multivariate analysis of covariance were conducted to assess the shortterm outcome of the intervention. Longer-term changes were assessed by a 
repeated measures 1 (group) x 3 (time: pre- vs. post- vs. follow-up) ANOVA. Statistical significance was taken at $p<.05$.

A sample size of 26 participants in each group is sufficient to detect large effect sizes, and hence groups of 20-25 are appropriate for a pilot investigation since only treatments with large effects are worthy of more comprehensive investigation.

\section{Results}

Demographic Information

The demographic characteristics of children and parents are reported in Table 1. Fifty-four percent of children were female and mean age was 10.0 years $(S D=1.9)$, with an average BMI of 26.8. Most children (71\%) were obese prior to treatment. Mean age of parents was 42.6 years $(S D=6.2)$ for mothers and 46.9 years $(S D=6.8)$ for fathers. The average BMI was $31.5(S D=9.1)$ for mothers and $32.0(S D=4.6)$ for fathers, with $43 \%$ of mothers and $63 \%$ of fathers classified as obese. There were no significant differences between the treatment and control group before treatment.

TABLE 1 NEAR HERE

\section{Pre- to Post-Treatment Changes}

Means of pre- to post-treatment BMI for children and parents are presented in Table 2. Repeated measures ANOVAs for BMI revealed an 
interaction between the groups $\left(F_{1,45}=22.05, p<0.001\right)$. As shown in Figure 3, children in the CAAT group showed a significant improvement in BMI $\left(t_{1,22}=4.81, p<0.001\right)$ that was not evident in the control group $\left(t_{1,23}=-1.47, p=0.16\right)$. There were no significant differences in parents' BMI over treatment.

\section{TABLE 2 NEAR HERE} FIGURE 3 NEAR HERE

\section{Follow-up}

There was a significant linear effect for BMI over time, indicating improvement $\left(F_{2,15}=7.63, p=0.01\right)$. However, post-hoc pair-wise comparisons revealed that the only significant change in BMI was between pre- and posttreatment $\left(t_{1,15}=4.02, p=0.001\right)$. The increase in BMI from post-treatment to followup was not significant $\left(t_{1,15}=-0.95, p=0.36\right)$, but neither was the decrease over the pre-treatment to follow-up period $\left(t_{1,15}=0.86, p=0.40\right)$.

No child moved from overweight to obese or obese to overweight during treatment in either group. Of the 17 children in the CAAT group at 6 month follow-up, 11/12 remained obese, 3/5 remained overweight, 2/5 changed from overweight to obese and 1/12 changed from obese to overweight, which represented no significant change $\left(t_{1,16}=-0.566, p=0.58\right)$. Repeated measures analysis revealed no significant difference between mothers' BMI $\left(F_{2,20}=0.007\right.$, $p=0.99)$ or fathers' BMI $\left(F_{2,10}=0.70, p=0.52\right)$ between the three test periods (pre-, post-, follow-up). 


\section{Discussion}

The aim of this research was to examine the efficacy of a 6-session CAAT program in the treatment of obese and overweight children. Short-term results indicated a significant reduction in BMI for children in the CAAT group compared to children in the control group. At follow-up, children in the CAAT group showed no evidence of further reduction in BMI. The CAAT group's BMI remained lower than at pre-treatment, despite a common trajectory in overweight children for their BMI to increase over time (24-26.). There were no significant changes in parents' BMI over the study period in either group.

The results of this study, while modest, are encouraging. The CAAT program used in this study was very brief and had no booster sessions. Furthermore, CAAT focused on helping children identify signals of hunger and satiety whilst little attempt was made to change the parent's behaviour. Consequently, there may have been little parental modelling of CAAT principles or generalization of the program content to parents. Indeed, parents (many of whom were overweight and obese) did not show a reduction in BMI over the testing period, which is consistent with the findings in Boutelle et al. (20.). Thus, in this context, it is striking that children as young as seven were able to learn to distinguish signals of hunger and satiety.

Although children in the CAAT group did not continue to show reductions in BMI following the program, treatment-related changes in BMI were maintained. This is a positive outcome in terms of stabilizing weight so that overweight 
children might 'grow into' their weight over time and contrasts with the significant increase in BMI found in the Boutelle et al (20.) study. Reasons for the discrepancy between studies are unclear; however, there were some differences between the approaches. Firstly, the current program was conducted in smaller groups, stratified for age and the majority of children (18/23) completed all sessions, whereas only $4 / 18$ children in the Boutelle (20) study attended all sessions. Also, in the Boutelle study, groups consisted of a range of additional cognitive-behavioural strategies, whereas in this study only CAAT skills were taught. It is therefore possible that despite the shorter course of treatment (6 vs 8 sessions) that the dose of appetite awareness training was greater in the present study. Further, such limited focus on specific content areas in the present version of CAAT may have an additional effect: it may enhance learning and retention. It is possible that given developmental constraints on the quantity of new material that can be learned, remembered and mastered during a therapeutic intervention that the limited focus on appetite awareness may have enhanced greater mastery of this skill. In contrast, interventions that teach multiple skills may dilute the effectiveness of acquisition of all skills. Such a proposition requires further study. Even so, children did not make clinically significant changes in weight status. This is a sub-optimal outcome but is nonetheless consistent with the acknowledged difficulty in this population of achieving long-term change (27-30.).

Despite careful attention to study design, there were several limitations which need to be considered when interpreting the results. Firstly, the intervention was very brief with no booster sessions during follow-up. Secondly, 
the intervention was developed for use with the children themselves, with parents in a supportive role. Some research suggests that treating parents alone may be more effective than treating the children (31.). Thirdly, the mechanisms which have contributed to changes in BMI are unknown, as data were only available for weight-related outcomes. Finally, the outcomes reported here are of statistical significance but there was little evidence of clinical significance. That is, not one child who was initially overweight or obese fell within the normal range following treatment. Hence, the outcomes are modest rather than ideal.

Despite these limitations, results suggest that a six-week cognitivebehavioural intervention focusing on appetite awareness shows promise for the treatment of overweight and obese children. Adequate examination of children's appetite awareness training will require more comprehensive and extended treatments than were offered in this pilot investigation. However, having demonstrated short-term gains, there is a good rationale for developing a more comprehensive treatment for children who are overweight and obese and examining its efficacy. 


\section{References}

1. Dietz W. Health consequences of obesity in youth: childhood predictors of adult disease. Pediatrics 1998;101:518.

2. World Health Organisation (WHO), Childhood overweight and obesity, WHO, 2010.

3. Dehghan M, Akhtar-Danesh N, Merchant AT. Childhood obesity, prevalence and prevention. Nutr J 2005;4:24.

4. Booth M, Wake M, Armstrong T, Chey T, Hesketh K, Mathur S. The epidemiology of overweight and obesity among Australian children and adolescents, 1995-97. Australian and New Zealand Journal of Public Health 2009;25:162-168.

5. Olds TS, Tomkinson GR, Ferrar KE, Maher CA. Trends in the prevalence of childhood overweight and obesity in Australia between 1985 and 2008. International Journal of Obesity 2009;34:57-66.

6. Rössner S. Childhood obesity and adulthood consequences. Acta Paediatrica 1998;87:1-5.

7. Zwiauer K, Caroli M, Malecka-Tendera E, Poskitt E. Clinical features, adverse effects and outcome. Child and adolescent obesity: Causes and consequences, prevention and management 2002:131-153.

8. Allen $\mathrm{H}$, Craighead L. Appetite monitoring in the treatment of binge eating disorder. Behavior Therapy 1999;30:253-272.

9. Klein JD, Dietz W. Childhood Obesity: The New Tobacco. Health Affairs 2010;29:388-392. 
10. Must A, Strauss RS. Risks and consequences of childhood and adolescent obesity. International Journal of Obesity 1999;23:S2-S11.

11. Epstein L, Valoski A, Wing R, McCurley J. Ten-year outcomes of behavioral family-based treatment for childhood obesity. Health Psychology 1994;13:373-383.

12. Croker H, Cooke L, Wardle J. Appetitive behaviours of children attending obesity treatment. Appetite 2011;57:525-529.

13. Tan CC, Holub SC. Children's Self-Regulation in Eating: Associations with Inhibitory Control and Parents' Feeding Behavior. Journal of Pediatric Psychology 2011;36:340-345.

14. Johnson S. Improving preschoolers' self-regulation of energy intake. Pediatrics 2000;106:1429.

15. Craighead L, Allen $\mathrm{H}$. Appetite awareness training: A cognitive behavioral intervention for binge eating. Cognitive and Behavioral Practice $1996 ; 2: 249-270$.

16. Appelhans BM. Neurobehavioral Inhibition of Reward-driven Feeding: Implications for Dieting and Obesity. Obesity 2009;17:640-647.

17. Wansink B, Payne CR, Chandon P. Internal and external cues of meal cessation: The French paradox redux? Obesity 2007;15:2920-2924.

18. Dicker S, Craighead L. Appetite-focused cognitive-behavioral therapy in the treatment of binge eating with purging. Cognitive and Behavioral Practice 2004;11:213-221. 
19. Hill DM. Appetite-focused dialectical behavior therapy for the treatment of binge eating with purging: A randomized controlled trial 2007.

20. Boutelle KN, Zucker NL, Peterson CB, Rydell SA, Cafri G, Harnack L. Two Novel Treatments to Reduce Overeating in Overweight Children: A Randomized Controlled Trial. Journal of Consulting and Clinical Psychology 2011;79:759-771.

21. Scaglioni S, Salvioni M, Galimberti C. Influence of parental attitudes in the development of children eating behaviour. British Journal of Nutrition 2008;99:22-25.

22. Cole TJ, Bellizzi MC, Flegal KM, Dietz WH. Establishing a standard definition for child overweight and obesity worldwide: international survey. British Medical Journal 2000;320:1240.

23. Burniat W, Cole T, Lissau I, Poskitt E, Child and adolescent obesity: Causes and consequences, prevention and management. Cambridge Univ Pr; 2002.

24. Power C, Thomas C. Changes in BMI, Duration of Overweight and Obesity, and Glucose Metabolism: 45 Years of Follow-up of a Birth Cohort. Diabetes Care 2011;34:1986-1991.

25. Raj M, Sundaram KR, Paul M, Sudhakar A, Kumar RK. Body mass index trend and its association with blood pressure distribution in children. Journal of Human Hypertension 2010;24:652-658.

26. Vuorela N, Saha M-T, Salo MK. Parents underestimate their child's overweight. Acta Paediatrica 2010;99:1374-1379. 
27. Epstein L, Myers M, Raynor H, Saelens B. Treatment of pediatric obesity. Pediatrics 1998;101:554.

28. Lopez L, Audisio Y, Berra S. Efectividad de las intervenciones de base poblacional dirigidas a la prevenci $\sqrt{ } \geq n$ del sobrepeso en la poblaci $\sqrt{\geq} \mathrm{n}$ infantil y adolescente (Effectiveness of population-based interventions on the prevention of overweight in children and adolescents). Medicina Clinica 2010;135:462-469.

29. Whitlock EP, O'Connor EA, Williams SB, Beil TL, Lutz KW. Effectiveness of Weight Management Interventions in Children: A Targeted Systematic Review for the USPSTF. Pediatrics 2010;125:E396-E418.

30. Gonzalez-Suarez C, Worley A, Grimmer-Somers K, Dones V. School-Based Interventions on Childhood Obesity A Meta-Analysis. American Journal of Preventive Medicine 2009;37:418-427.

31. Golan M, Kaufman V, Shahar DR. Childhood obesity treatment: targeting parents exclusively v. parents and children. Br J Nutr 2006;95:1008-1015. 
Figure 1. Flow of participants through randomized-controlled trial

Figure 2. Hunger meter.

Figure 3. BMI change in children over treatment/wait-list period and follow-up. 


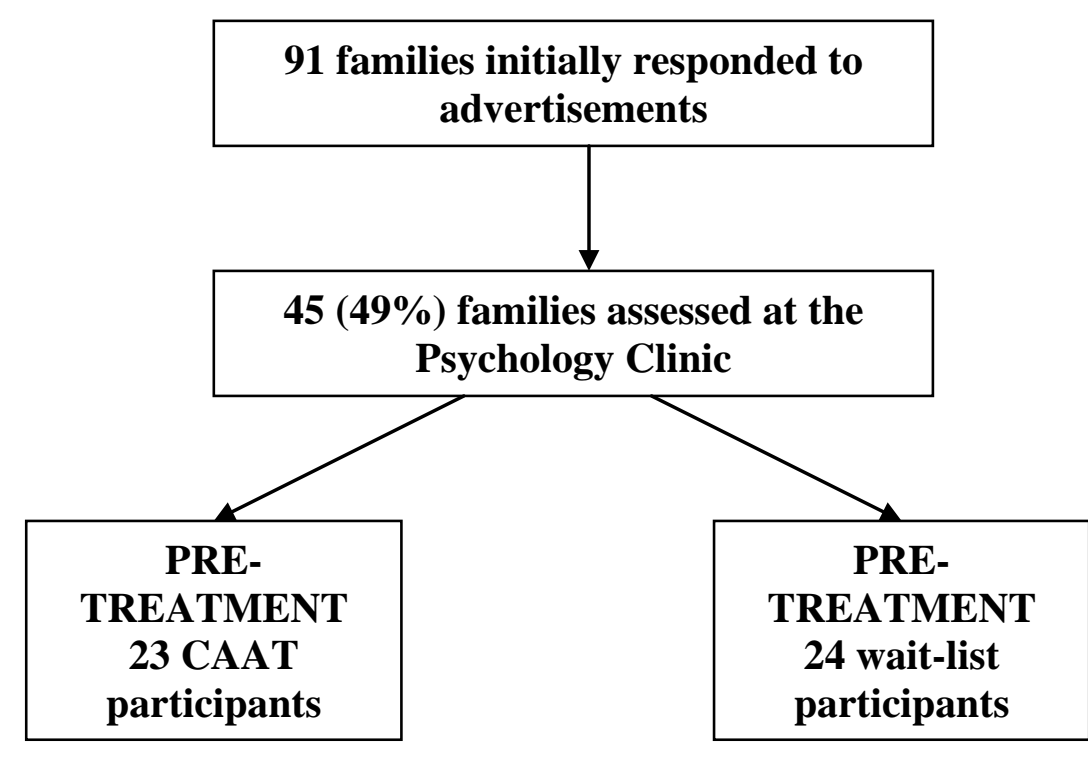

\begin{tabular}{|c|}
\hline POST- \\
TREATMENT \\
23 CAAT \\
participants \\
\hline
\end{tabular}

\begin{tabular}{|c|}
\hline POST- \\
TREATMENT \\
24 wait-list \\
participants \\
\hline
\end{tabular}

\begin{tabular}{|c|}
\hline 6 MONTH \\
FOLLOW-UP \\
17 CAAT \\
participants \\
\hline
\end{tabular}

WAIT-LIST

OFFERED

TREATMENT 


\section{FIGURE 2}

\begin{tabular}{|c|c|c|c|c|}
\hline Starving & Hungry & Neutral & Satisfied & Stuffed \\
\hline 1 & $\begin{array}{c}\text { start } \\
\text { eating } \\
\text { here }\end{array}$ & 3 & $\begin{array}{c}\text { stop } \\
\text { eating } \\
\text { here }\end{array}$ & \\
\hline $\begin{array}{l}\text { Very, very hungry- } \\
\text { too hungry!l You } \\
\text { may feel weok, } \\
\text { your stomach may } \\
\text { hurt, or you may } \\
\text { have a heodache. }\end{array}$ & $\begin{array}{l}\text { Your stomach feels } \\
\text { empty and maybe } \\
\text { growling. You are } \\
\text { reody to eat! }\end{array}$ & $\begin{array}{l}\text { You are not hungry } \\
\text { but not yet } \\
\text { satisfied! }\end{array}$ & $\begin{array}{l}\text { You are not hungry } \\
\text { and you may feel } \\
\text { uncomfortable if } \\
\text { you ate more. }\end{array}$ & $\begin{array}{l}\text { You feel a little } \\
\text { foo full and you } \\
\text { feel } \\
\text { uncomfortable. }\end{array}$ \\
\hline
\end{tabular}


FIGURE 3

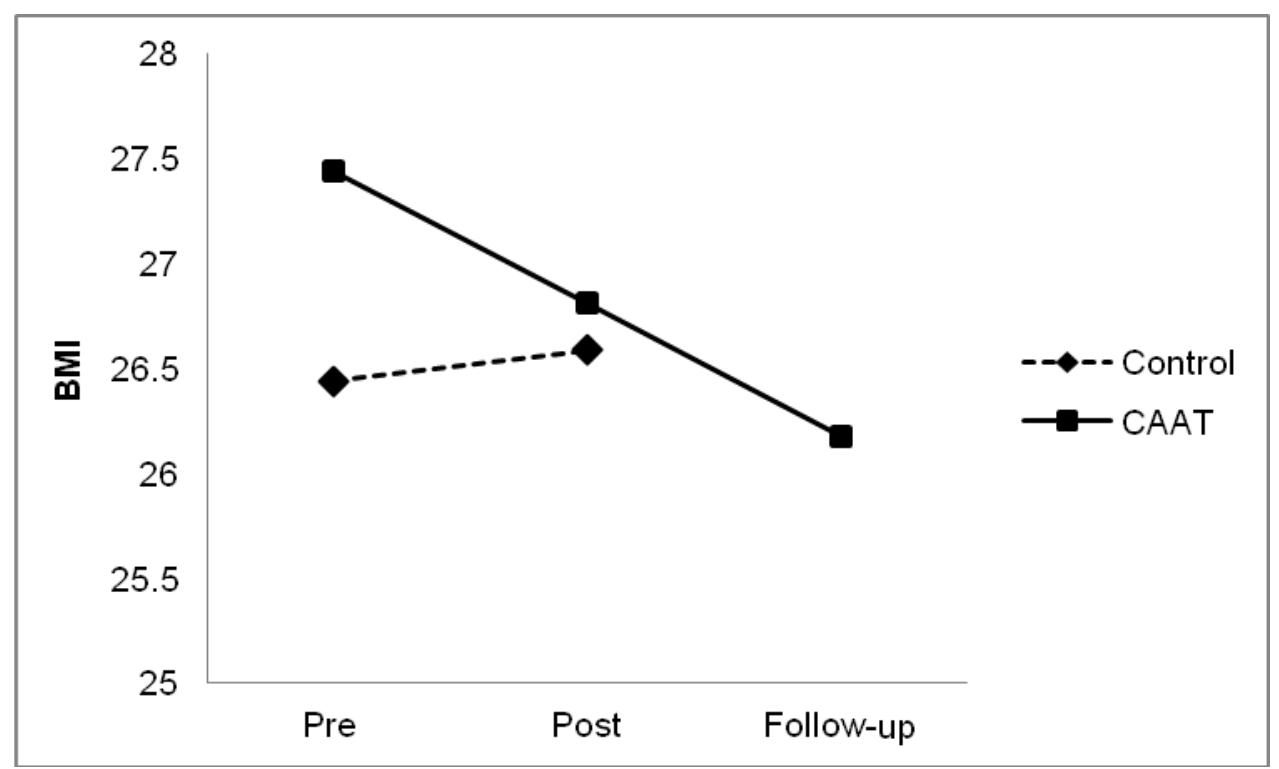


Table 1. Summary of participant characteristics for randomized-controlled trial.

\begin{tabular}{lccc}
\hline Measure & Child M(SD) & Mother M(SD) & Father M(SD) \\
& $n=45$ & $n=41$ & $n=30$ \\
\hline Age (years) & $10(1.9)$ & $42.6(6.2)$ & $46.9(6.8)$ \\
Weight (kilograms) & $56.8(13.4)$ & $82.1(27.1)$ & $96.7(12.8)$ \\
BMI & $26.8(4.3)$ & $31.5(9.1)$ & $32(4.6)$ \\
\% Normal/Overweight/Obese & $0 / 29 / 71^{1}$ & $29 / 29 / 41^{2}$ & $11 / 26 / 63^{2}$ \\
Gender (\%Male) & $54 \%$ & & \\
\hline
\end{tabular}

${ }^{1}$ Overweight in children is defined by an age related BMI above the BMI centile passing through BMI values of $25 \mathrm{~kg} / \mathrm{m}^{2}$ at age 18 years, whilst obese is defined by an age related $\mathrm{BMI}$ above the BMI centile passing through BMI values of $30 \mathrm{~kg} / \mathrm{m}^{2}$ at age 18 years (Cole et al., 2000).

2 Overweight in adults is defined by a BMI greater than $25 \mathrm{~kg} / \mathrm{m}^{2}$, whilst obese is defined as a BMI greater than $30 \mathrm{~kg} / \mathrm{m}^{2}$ (WHO, 1997). 
Table 2. Weight and BMI for children and parents in control and treatment groups at pre-post and follow-up.

\begin{tabular}{|c|c|c|c|}
\hline Measure & Pre-treatment & Post-treatment & Follow-up \\
\hline & $\mathrm{M}(S D)$ & $\mathrm{M}(S D)$ & $M(S D)$ \\
\hline Children (Treatment group) & $n=23$ & $n=23$ & $\mathrm{n}=17$ \\
\hline BMI $\left(\mathrm{kg} / \mathrm{m}^{2}\right)$ & $27.44(3.9)$ & 26.81(3.91) & $26.18(3.31)$ \\
\hline Children (control group) & $\mathrm{n}=24$ & $n=24$ & \\
\hline BMI $\left(\mathrm{kg} / \mathrm{m}^{2}\right)$ & $26.44(3.76)$ & $26.59(3.57)$ & \\
\hline Mothers (Treatment group) & $\mathrm{n}=22$ & $\mathrm{n}=21$ & $n=11$ \\
\hline BMI $\left(\mathrm{kg} / \mathrm{m}^{2}\right)$ & $30.72(8.39)$ & $30.75(8.53)$ & $30.08(6.64)$ \\
\hline Mothers (Control group) & $\mathrm{n}=23$ & $n=23$ & \\
\hline BMI $\left(\mathrm{kg} / \mathrm{m}^{2}\right)$ & $30.47(8.4)$ & $30.65(8.3)$ & \\
\hline Fathers (Treatment group) & $\mathrm{n}=16$ & $\mathrm{n}=16$ & $n=6$ \\
\hline BMI $\left(\mathrm{kg} / \mathrm{m}^{2}\right)$ & $31.43(4.28)$ & 31.05(3.93) & $31.01(4.7)$ \\
\hline Fathers (Control group) & $\mathrm{n}=18$ & $\mathrm{n}=15$ & \\
\hline BMI $\left(\mathrm{kg} / \mathrm{m}^{2}\right)$ & $32.25(4.48)$ & $31.82(4.63)$ & \\
\hline
\end{tabular}

